\title{
INTERNACIONALIZAÇÃO DOS SISTEMAS DE AVALIAÇÃO: EVIDÊNCIAS DE BRASIL E CHILE
}

\author{
INTERNACIONALIZACIÓN DE LOS SISTEMAS DE EVALUACIÓN: EVIDENCIAS \\ DE BRASIL Y CHILE
}

\section{INTERNATIONALIZATION OF ASSESSMENT SYSTEMS: EVIDENCE OF BRAZIL AND CHILE}

\author{
Fabiano Antonio dos SANTOS ${ }^{1}$ \\ María Teresa Flórez PETOUR ${ }^{2}$
}

RESUMO: O artigo sugere a existência de uma agenda internacional para a educação, promovida pelas Organizações Internacionais, a partir da qual se promove a expansão de sistemas de avaliação da qualidade da educação. O estudo foi realizado a partir de análises de documentos internacionais e nacionais que tratam sobre as avaliações externas nos sistemas educacionais do Brasil e Chile. Em particular, analisaram-se documentos de política educacional centrados no Índice de Desenvolvimento da Educação Básica, no Brasil, e no Sistema de Medição da Qualidade da Educação, no Chile. As análises evidenciam a presença de estratégias ideológico-discursivas comuns entre as Organizações Internacionais e as elites políticas locais, que apontam a legitimidade e naturalização dos sistemas de avaliação da qualidade, assim como do contexto político em que se inserem, apagando de sua textualidade possíveis resistências e discursos alternativos.

PALAVRAS-CHAVE: Avaliação. Internacionalização. Chile. Brasil.

RESUMEN: El artículo plantea la existencia de una agenda internacional para la educación, promovida por las Organizaciones Internacionales, a partir de la cual se promueve la expansión de sistemas de evaluación de la calidad de la educación. El estudio fue realizado a partir del análisis de documentos internacionales y nacionales que tratan sobre las evaluaciones externas en los sistemas educacionales de Brasil y Chile. En particular, se analizaron documentos de política educacional centrados en el Índice de Desarrollo de la Educación Básica, en Brasil, y en el Sistema de Medición de la Calidad de la Educación, en Chile. El análisis evidencia la presencia de estrategias ideológico-discursivas comunes entre las Organizaciones Internacionales y las elites políticas locales, que apuntan a la legitimación y naturalización de los sistemas de evaluación de la calidad, así como del contexto político en que se insertan, borrando de su textualidad posibles resistencias y discursos alternativos.

PALABRAS CLAVE: Evaluación. Internacionalización. Chile. Brasil.

\footnotetext{
${ }^{1}$ Universidade Federal de Mato Grosso do Sul (UFMS), Corumbá - MS - Brasil. Professor do Curso de Pedagogia e do Programa de Pós-graduação em educação (PPGE/CPAN). ORCID: https://orcid.org/0000-0002-7703-8520. E-mail: fabiano.santos@ufms.br

${ }^{2}$ Universidade do Chile - (UChile), Faculdade de Filosofia e Humanidades, Santiago - Chile. Professora Assistente do Departamento de Estudos Pedagógicos da Universidade do Chile, na área de Avaliação de e para a Aprendizagem. ORCID: https://orcid.org/0000-0003-3704-726X. E-mail: mtflorez@u.uchile.cl
}

RIAEE - Revista Ibero-Americana de Estudos em Educação, Araraquara, v. 14, n. esp. 3, p. 1829-1846, out., 2019. E-ISSN: $1982-5587$. 
ABSTRACT: The article suggests that there is an international agenda for education, promoted by the International Organizations, which promotes the expansion of evaluation systems of education quality. The study was conducted based on the analysis of both international and national documents that deal with external assessments in both Brazil's and Chile's educational systems. In particular, they analyzed the educational policy documents focused on the Basic Education Development's Index, in Brazil, and in the System of Education Quality Measurement, in Chile. The results of the analysis show evidence of a common ideological speech strategy between the International Organizations and the local political elites, which indicate the legitimacy and naturalization of the education quality measurement's systems, as well as, the political context that is inserted, removing from its textuality possible resistances and alternative speeches.

KEYWORDS: Assessments. Internationalization. Chile. Brazil.

\section{Introdução}

O artigo busca evidenciar a presença de uma Agenda Globalmente Estruturada (DALE, 2000) em expansão a partir de dois casos correspondentes aos principais sistemas de avaliação no Brasil e Chile: o Sistema de Avaliação da Educação Básica (SAEB) e o Sistema de Medição da Qualidade da Educação (SIMCE), respectivamente. Cabe assinalar que os resultados aqui apresentados correspondem a processos realizados separadamente pelos autores, e se colocam em diálogo com a finalidade de detectar padrões comuns entre ambos os contextos, em termos de suas relações com os Organismos Internacionais (OIs), a partir da construção de discursos comuns sobre as discussões e políticas de avaliação da qualidade da educação.

Da análise dos documentos internacionais e nacionais, deriva-se clara relação entre os documentos elaborados pelos OIs e os documentos nacionais de Brasil e Chile. Esta relação evidencia-se através da presença de discursos e estratégias comuns entre os OIs e o nível local, dentre os quais destacamos: 1) naturalização das condições do sistema educacional e da avaliação e seus efeitos positivos; 2) o estabelecimento dos sistemas de avaliação da qualidade da educação como necessários e inevitáveis; 3) esvaziamento do conceito de qualidade e a equivalência deste com a ideia de resultados da aprendizagem; 4) a geração da ilusão de consenso; 5) a introdução da ideia de que 'todos a fazem' como fundamento; 6) a responsabilização dos usuários da avaliação pelos problemas destes sistemas. O caráter ideológico destas estratégias se revela na falta de fundamentos concretos sobre a base de evidências para seu estabelecimento, o que manifesta o caráter retórico destes argumentos. 


\section{Internacionalização da educação: Organizações internacionais e a instalação de uma Agenda Globalmente Estruturada}

Existe toda uma linha de estudos sobre internacionalização das políticas educacionais que apresenta este processo como natural, isto é, um consenso crescente de que haveria surgido, nas últimas décadas, entre diferentes países do mundo, práticas educativas consideradas boas para a educação. Desde essa perspectiva, a internacionalização é entendida como uma tendência espontânea em um mundo cada vez mais globalizado e descentralizado, onde o conhecimento e os valores relacionados à educação podem ser compartilhados entre os diversos contextos nacionais, com a finalidade de melhorar a educação em nível mundial. Estes autores tendem a assumir este novo cenário como uma realidade dada, na qual

Ao redor de todo o mundo os governos, as universidades, os sistemas escolares
e as diversas partes envolvidas estão buscando novas formas de encontrar,
compartilhar, compreender e aplicar o conhecimento que emerge da
investigação, o qual tem levado a um trabalho conceitual e empírico crescente
para compreender como isto pode se realizar. (LEVIN, 2011, p. 5, tradução
nossa)

Aqueles que se situam nesta corrente avaliam os novos cenários de governança transnacional como positivos, contexto no qual instrumentos como PISA, TIMSS e outros similares são ferramentas que promovem "uma janela adicional de oportunidades para superar a acumulação de reformas estruturais pendentes" no nível nacional (DOBBINS, 2012, p. 37). Para autores como Campbell \& Levin (2009), a realização de tests e informes educacionais contribuem para a transparência e permitem a melhoria permanente. A nível global, estes sistemas de geração de informação se conectam com a ideia de economia do conhecimento, já que o monitoramento de resultados permitiria o melhoramento da educação, entendida como meio para incrementar a competitividade econômica das nações.

Seguindo a caracterização de autores como Schriewer \& Martínez (2004), esta perspectiva é aproximada com aquilo que se conhece como corrente neo-institucionalista na análise da política educacional. Esta linha acredita na emergência gradual de um sistema mundial, onde surgem padrões convergentes em uma espécie de cultural e ideologia mundial educacional, a qual se encontraria em expansão entre os diversos atores do sistema e responderia às tendências de modernização que ocorrem, cedo ou tarde, em todos os países.

Essa perspectiva, amplamente difundida entre os OIs membros das elites políticas, é questionada a partir de aproximações teóricas e investigativas mais próximas à sociologia e estudos críticos das políticas educacionais. Autores como Roger Dale (2000) contrapõem a ideia de uma Cultura Educacional Mundial Comum à de uma Agenda Globalmente Estruturada, 
em que a ideia de um consenso supranacional espontâneo é substituída pelo reconhecimento de forças econômicas e sociais orientadas à organização da economia global em função da manutenção do status quo capitalista, isto é, trata-se da expansão global de uma agenda política específica.

A tentativa de construir esta agenda internacional vem se realizando desde a criação dos OIs, mas a partir dos anos 1990 ganhou destaque e prioridade. Desde os anos 1990, em especial com a realização da Conferência Mundial sobre Educação Para Todos, realizada na cidade de Jomtien - Tailândia, é possível perceber crescente processo de homogeneização das recomendações advindas das Organizações Internacionais para o setor educacional. Diferentemente da perspectiva neo-institucionalista que, como vimos, defende a existência de uma convergência quase natural de interesses entre os mais diversos países, o que se evidencia, ao realizarmos uma análise mais crítica, é a existência de uma agenda internacional para a educação, convergente aos interesses neoliberais de globalização e mundialização do capital.

Essa agenda atravessa, ao mesmo tempo, dois momentos distintos e complementares: a ênfase sobre a universalização do ensino básico para os países periféricos e a preocupação com a qualidade da educação. Enquanto a primeira proposta acompanhava o próprio desenvolvimento das Organizações Internacionais, que passavam a se preocupar mais com áreas antes consideradas de menor importância, como educação, saúde e seguridade social, a segunda mostra-se complementar à primeira, sendo impulsionada pela constatação que países como o Brasil, Chile e outros da América Latina e Caribe haviam atingido taxas superiores a 90\% de cobertura da educação básica, mas que ainda faltariam formas de mensurar a real aprendizagem dos alunos. A partir desta nova perspectiva, um processo intenso de (des)centralização da escola ganha destaque, revelando uma nova tendência das políticas em focar ações mais diretas e pontuais (um verdadeiro processo de colonização).

A colonização do conceito de qualidade passa a dominar o discurso dos reformadores, caracterizando que o problema deixava de ser a cobertura da educação básica e passava a ser a qualidade da aprendizagem. Nesta perspectiva, associa-se qualidade da educação e aprendizagem à qualidade do professor, à forma como a escola realiza sua gestão.

Os esforços das reformas educacionais das últimas duas décadas têm revelado seus limites (CARNOY, 2007; TEDESCO, 2007); estas não afetaram de maneira efetiva e com escala suficiente o núcleo do quefazer docente em aulas e escolas. As capacidades e desempenhos de docentes e de diretores de escolas, reconhecidamente o núcleo mais duro em qualquer esforço de reforma (FULLAN, 2003), são o centro da nova agenda. As novas políticas educativas deveriam centrar-se na agenda de mudanças das capacidades daqueles que dependem dos desempenhos docentes nas aulas e diretores nos 
centros, assim como nos resultados de aprendizagem de alunos e sistemas escolares (SCHWARZMAN; COX, 2009, p. 15-16, tradução nossa).

Esta agenda global para a educação tem o objetivo de homogeneizar padrões e práticas escolares, aproximar, quando não tornar idênticos, objetivos de aprendizagem, estratégias de ensino, prioridades em relação ao financiamento e à formação de professores. Em outras palavras, a atenção que recebem as escolas, a partir de meados dos anos 1990, reflete na forma como estas passam a realizar sua própria gestão.

\begin{abstract}
As reformas educativas em marcha situam a escola como eixo fundamental de mudanças. Durante a década de noventa, um significativo número de países outorgou maior autonomia às escolas para tomada de decisões pedagógicas e de gestão. O alcance e grau de autonomia na tomada de decisões variam segundo os países, ainda que seja possível identificar três tendências: autonomia somente para as decisões pedagógicas e curriculares; autonomia na administração de recursos, e financeiro em alguns casos, e autonomia em ambos os aspectos. O argumento fundamental para potencializar a autonomia escolar é que a participação da comunidade na gestão das escolas contribui para melhorar a qualidade e eficiência da educação ao realiza-la com maior pertinência às necessidades reais de cada contexto (UNESCO/OREALC, 2001, p. 59, tradução nossa).
\end{abstract}

Em nome de uma suposta qualidade da educação, uma verdadeira avalanche de medidas atinge as escolas da América Latina e Caribe. São projetos, propostas de reformas, mudanças na proposição de contratação de professores, novas sugestões para recrutar professores mais "qualificados", além de consolidação de sistemas de avaliação com altas consequências para as escolas e seus sujeitos. A orientação, nesta perspectiva, é associar uma aprendizagem de qualidade aos índices alcançados nas avaliações estandardizadas.

Contreras (2002) afirma que esses conceitos se tornam tão aceitos entre os sujeitos escolares e sociedade em geral que parecem ter uma aura positiva, tornam-se verdadeiros slogans.

\begin{abstract}
Pode-se dizer que, por serem slogans, são utilizados em excesso para provocar uma atração emocional, sem esclarecer nunca o significado que se lhes quer atribuir. Funcionam assim como palavras com aura, que evocam ideias que parecem positivas e ao redor das quais se pretende criar consenso e identificação (CONTRERAS, 2002, p. 23, grifos no original).
\end{abstract}

Esses slogans acabam ocultando posicionamentos divergentes, não manifestam as pretensões antagônicas, dão a impressão de que, uma vez mencionados, a aceitação deveria ser imediata, e quem os contesta é considerado contrário ao desenvolvimento e progresso da educação. 
Em Dakar, nos anos 2000, o Fórum Mundial, sobre a Educação para Todos, retoma os compromissos firmados nos anos 1990, mas com o foco no rendimento escolar, visto que o capitalismo como conhecemos estava plenamente desenvolvido.

A perspectiva de Jontiem segue sendo pertinente e eficaz. Em efeito, facilita uma visão ampla e geral da educação e seu papel determinante para preparar os indivíduos e transformar a sociedade. Seus pontos e princípios essenciais são seguintes: generalização do acesso à educação; insistência na igualdade; ênfase nos resultados da aprendizagem (UNESCO, 2000, p.12, tradução nossa).

A ênfase dada aos resultados na aprendizagem pode ser vista no esforço de se criar mecanismos de avaliação que mensurem o rendimento escolar, por consequência, estabeleça metas e parâmetros na qualidade do ensino.

Para alcançar os objetivos da Educação para Todos, é necessário definir prioridades, definir políticas, estabelecer objetivos e indicadores de avanço, atribuir recursos, supervisionar o rendimento e avaliar os resultados quantitativos e qualitativos. É essencial dispor de números estatísticos confiáveis, desagregados e baseados em dados exatos obtidos pelo censo, se quiser avaliar corretamente e construir os ensinamentos (UNESCO, 2000 p.21, tradução nossa).

Ao associar o conceito de qualidade da educação a formas de mensurá-la, acaba-se naturalizando a ideia de que uma educação de qualidade é aquela em que os resultados nas avaliações externas logram altas pontuações. Por consequência, assim como a qualidade é um conceito aparentemente neutro e inquestionável, a avaliação passa a constituir lugar comum, pouco debatido e questionado.

Contribui significativamente para essa colonização da qualidade associada à avaliação o discurso difundido pelas Organizações Internacionais. Apontam como inevitável a relação entre qualidade e avaliação:

Como o processo educativo é prolongado em termos de tempo, devem ser fazer controles intermediários para assegurar que as crianças estejam aprendendo bem e, assim, evitar que aprendizagens de má qualidade sigam no processo sem que se corrijam seus defeitos e se fazer um controle final para assegurar que os jovens estejam aprendendo de acordo com as necessidades e expectativas da sociedade (UNESCO, 1997, p. 4, tradução nossa).

A educação só teria qualidade se passasse por avaliações contínuas, que mensurassem o que os estudantes estão aprendendo. Nessa mesma lógica de convencimento, aponta-se para uma visão bastante restrita em termos de avaliação, uma visão até dualista e simplista apresentada de duas formas: uma que continuaria a trabalhar com a aprendizagem dos 
estudantes sem saber ao certo se o caminho traçado estaria correto e outra visão em que as avaliações seriam a guia para mostrar o caminho correto para a aprendizagem.

Portanto, os sistemas educativos podem se organizar de duas formas. Uma é continuar ensinando às crianças sem obter informação do que estão aprendendo. A outra é instituindo um sistema nacional de medição do rendimento acadêmico para supervisionar a aprendizagem do estudante e obter informação para melhorá-lo. Se bem que hoje em dia, a maioria dos sistemas educativos está organizada da primeira maneira, a situação está mudando. Muitos países, entre os quais se encontram vários da América Latina, têm reconhecido as possibilidades oferecidas pela medição do rendimento acadêmico como base para melhorar a qualidade da educação (UNESCO, 1997, p. 6, tradução nossa).

Desde essa perspectiva, a avaliação garantiria o estabelecimento de dados quantitativos e melhoria no planejamento das escolas, uma vez que a partir dos resultados alcançados poderse-ia traçar os objetivos futuros. A qualidade, quando vinculada desta maneira com as avaliações externas, se reduz a um elemento simples de negociação, uma ferramenta poderosa de controle e diferenciação social.

\section{A agenda Globalmente Estruturada a nível local: SAEB e SIMCE}

Como forma de exemplificar os processos de expansão de uma agenda Globalmente Estruturada, serão analisados uma série de documentos de política educacional local, observando a forma em que replicam as estratégias já mencionadas como características da agenda promovida pelas OIs. Estes documentos referem-se aos principais sistemas de avaliação da qualidade da educação instaurados no Brasil e Chile: o Sistema de Avaliação da Educação Básica (SAEB) e o Sistema de Medição da Qualidade da Educação (SIMCE), respectivamente.

O SAEB foi desenvolvido pelo Instituto Nacional de Estudos e Pesquisas Anísio Teixeira (INEP) em 1990 e avaliava, de forma amostral, alunos da $1^{\mathrm{a}}, 3^{\mathrm{a}}, 5^{\mathrm{a}}$ e $7^{\mathrm{a}}$ séries do ensino fundamental. A partir de 1997 as turmas avaliadas passam a ser a $4^{\mathrm{a}}$ e $8^{\mathrm{a}}$ séries do ensino fundamental e $3^{\circ}$ ano do Ensino Médio, também de forma amostral. Nestes quase trinta anos, o Saeb enfrentou diversas estruturações, sendo a principal em 2005, quando passou a ser composto por duas avaliações: a Avaliação Nacional da Educação Básica (Aneb), com as mesmas características desde os anos 1990, e a Avaliação Nacional do Rendimento Escolar (Anresc), conhecida como Prova Brasil. De maneira geral, as avaliações mensuram conhecimentos em Linguagem, Matemática e ciências naturais (os resultados destas últimas não são divulgados). Assim como ocorre com o SIMCE, a partir de 2013 a educação infantil 
passa a ser avaliada com a criação da Avaliação Nacional da Alfabetização (ANA), também incorporada no Saeb (BONAMINO; FRANCO, 1999). Com essa avaliação, todas as etapas da educação brasileira passam a ser avaliadas periodicamente (a cada dois anos). O resultado das avaliações, somados aos dados censitários de aprovação obtidos no Censo Escolar formam o Índice de Desenvolvimento da Educação Básica (IDEB).

O IDEB tem como elementos constituintes: “a) indicadores de fluxo (promoção, repetência e evasão) e b) pontuações em exames padronizados obtidas por estudantes ao final de determinada etapa do sistema de ensino ( $4^{\mathrm{a}}$ e $8^{\mathrm{a}}$ séries do ensino fundamental e $3^{\mathrm{o}}$ ano)" (BRASIL, 2007).

O Saeb é uma avaliação censitária e, justamente por isso, permite a definição de um índice por escola e, consequentemente, a instituição de ranking comparativo entre as demais escolas da rede de ensino. A prova aos moldes censitários torna-se muito mais prejudicial ao desenvolvimento autônomo das escolas. Por outro lado, estas mesmas avaliações poderiam ser aplicadas adotando a estratégia amostral, o que poderia conferir resultados tão significativos quanto a estratégia censitária, mas com impactos menos negativos sobre o trabalho escolar.

Já o SIMCE foi criado em 1988 e estabelecido por lei em 1990, a partir da Lei Orgânica Constitucional de Ensino (LOCE), promulgada pelo governo ditatorial de Pinochet dias antes de finalizar sua administração. Ainda que tenha antecedentes em outras provas criadas anteriormente (SCHIEFEKBEIN, 1998), é a primeira avaliação centrada em informar aos pais sobre a qualidade da educação oferecida pelas escolas em um contexto de educação de mercado e da imposição de uma ideologia neoliberal em educação (BELLEI, 2015). Trata-se de uma avaliação censitária realizada, inicialmente, por todos os estudantes de $4^{\circ}$ e $8^{\circ}$ nível primário e por todos os de $2^{\circ}$ ano secundário nas áreas de linguagem e matemática e, posteriormente incorporadas as áreas de História e Ciências naturais para as series da educação primária, considerando apenas um nível por ano.

Com a intensificação das políticas neoliberais - tanto os governos de terceira via como de direita, durante os últimos 30 anos (BELLEI, 2015) - as provas foram aumentando gradualmente em termos de áreas e níveis cobertos, até chegar a um cenário em que, durante o ano de 2014, foram realizadas em torno de 17 provas nos estabelecimentos chilenos. Junto a esse crescimento, houve um aumento gradual das consequências e incentivos associados às provas, partindo da publicação de resultados a partir de 1995, seguido de diversas bonificações e incentivos econômicos associados aos resultados, aos quais se agregam recentemente classificações da escola que implicam, inclusive, a possibilidade de intervenção e eventual fechamento. A partir de 2015 houve diminuição destas provas como resposta ao 
descontentamento manifestado por diversos atores sociais (COMISIÓN SIMCE, 2015), embora continue em uma quantidade maior à estabelecida em seu princípio e com manutenção da pressão e das consequências que este sistema gera nas escolas.

O SIMCE foi inicialmente desenvolvido e aplicado pela Pontifícia Universidade Católica do Chile (PUC), em convênio com o Ministério de Educação (MINEDUC). Desde 1993, passou a ser aplicado diretamente pelo MINEDUC. Posteriormente, com a criação da Agência de Qualidade da Educação, um organismo governamental independente do MINEDUC, o SIMCE passa, em 2012, a ser administrado por esta nova entidade.

$\mathrm{Na}$ sequência deste texto, serão analisados alguns fragmentos ilustrativos de documentos de política local, referindo-se ao SAEB e SIMCE em conexão com cada uma das estratégias assinaladas anteriormente como pertencentes aos OIs e sua promoção de uma Agenda Globalmente Estruturada.

\section{Naturalização das condições contextuais e efeitos positivos da avaliação}

No caso do Brasil, os documentos que tratam das avaliações locais apresentam-nas como se não pertencessem a um contexto político e econômico complexo, desigual, e, por isso mesmo, gerador de avaliações igualmente desiguais. Neste sentido, as avaliações parecem apresentar caminhos que, até então, não se havia encontrado. Ainda que reconheçam haver problemas estruturais, afirmam que estes não dizem respeito diretamente à escola, que deveria se preocupar com o ensino independentemente de classes sociais, contextos econômicos, políticos e culturais.

\footnotetext{
Aquilo que se refere à escola situa-se dentro das possibilidades de intervenção dos gestores de políticas públicas educacionais. Nesse sentido, a escola passa a ser uma instituição fundamental para promover a equidade, bem como proporcionar o desenvolvimento dos saberes básicos, contribuindo para a inclusão social e econômica do cidadão, independentemente da sua origem social. Portanto, uma boa escola é aquela que permite o aprendizado, com qualidade e para todos. Os fatores extraescolares dependem de macropolíticas que interfiram nas condições das famílias e no combate à exclusão social; estariam, stricto sensu, fora do âmbito de uma política educacional [...] (ARAÚJO; LUZIO, 2005, p. 60-61).
}

Se assume que os resultados positivos das avaliações resolveriam os contextos mais amplos, como se o importante fosse resolver os problemas de aprendizagem (aprendizagem na perspectiva das OIs, quer dizer, relacionada ao sucesso nas avaliações externas), não cabendo reflexões sobre os motivadores dos problemas de aprendizagem. Outros documentos brasileiros 
seguem a mesma ordem (BRASIL, 2004; 2013) e apresentam apenas os pontos positivos das avaliações, não contextualizam as dificuldades que é estabelecer uma escola que esteja efetivamente preparada para enfrentar os problemas sociais e econômicos.

No caso do Chile, a maioria dos documentos de política educacional local analisados limitam-se a realizar um resgate histórico do desenvolvimento dos sistemas de avaliação a nível nacional até chegar ao SIMCE, sem haver qualquer menção do projeto político-ideológico que os inspirou, concentrando, assim, sua atenção mais aos aspectos técnicos e numa visão imanentista do sistema de avaliação e sua evolução (ver, por exemplo HIMMEL, 1997; MECKES, 2003; BRAVO, 2011). Em outros casos, há simplesmente omissão do contexto, e o texto refere-se diretamente às características, vantagens e desvantagens do sistema (ver, por exemplo, EYZAGUIRRE; FONTAINE, 1999; COMISIÓN SIMCE, 2015). Uma variante destas estratégias pode ser encontrada em Cox (2003), que situa a origem destas políticas no governo militar autoritário, mas o faz desde uma apresentação positiva das políticas de terceira via de governos de centro-esquerda. Os fatores de continuidades entre ambos os governos são descritos como "componentes organizacionais e de financiamento (COX, 2003, p. 2, tradução nossa), neutralizando, assim, a natureza político-ideológica da continuidade das políticas da ditadura.

$\mathrm{Na}$ mesma linha, vários documentos brasileiros e chilenos naturalizam os efeitos positivos do SAEB e SIMCE, apresentando-os como amplamente aceitos. As citações abaixo oferecem exemplos ilustrativos desta estratégia amplamente estendida aos documentos analisados:

Tem-se a convicção de que os dados produzidos a partir da avaliação educacional podem subsidiar, de forma efetiva, ações em prol de melhorias na qualidade do aprendizado e das oportunidades educacionais oferecidas à sociedade brasileira. A avaliação gera medidas que permitem verificar a efetividade dos sistemas de ensino em atingir patamares aceitáveis de desempenho, refletindo melhor desenvolvimento cognitivo dos estudantes. Por meio do levantamento de dados da avaliação são construídas medidas contextuais, além das de aprendizagem, que indicam quais fatores da escola, de sua gestão e dos seus docentes contribuem para um melhor aprendizado (ARAÚJO; LÚZIO, 2005, p. 9).

O Sistema de Avaliação da Educação Básica - SAEB, instituído em 1990, tem como principal objetivo realizar um diagnóstico da educação básica brasileira. O levantamento produz informações que subsidiam a formulação, reformulação e o monitoramento das políticas públicas nas esferas municipal, estadual e federal, visando a contribuir para a melhoria da qualidade, equidade e eficiência do ensino. Além disso, procura também oferecer dados e indicadores sobre fatores de influência no desempenho dos estudantes nas áreas e anos avaliados. Desde sua implantação, o SAEB estruturou-se com o 
objetivo principal de oferecer subsídios para a formulação, reformulação e monitoramento de políticas públicas (BRASIL, 2019, p. 2).

É conhecida a influência dos programas de avaliação com altas consequências em motivar as mudanças educacionais. O SIMCE é um sistema de mensuração de altas consequências para as escolas, na medida que seus resultados se azem públicos e podem ter incidência na matrícula e consequentemente no financiamento das escolas. Neste sentido, o SIMCE foi concebido como um dos agentes relevantes no processo de reforma, desempenhando papel [importante] na direção e motivação da implementação do currículo (MECKES, 2003, p. 162, tradução nossa).

Além disso, os resultados das avaliações permitiram a retroalimentação das práticas pedagógicas e de gestão nos estabelecimentos, por meio da distribuição de relatórios para docentes e diretores, da organização de seminários de difusão dos resultados e da realização de jornadas de análises nos estabelecimentos educacionais (BRAVO, 2011, p. 190, tradução nossa).

Há uma apresentação positiva das consequências do SAEB e SIMCE, que são associadas, nas citações, a uma maior 'motivação' dos atores do sistema, assim como à contribuição dos resultados ao melhoramento das práticas pedagógicas e sua qualidade. Isto não está fundamentado em evidências, mas como um fato, o que converte estas estratégias em dispositivos ideológicos. Ignora-se, ou omite-se, a afirmação de crescente evidencia acerca das consequências e experiências negativas que a pressão imposta pelas políticas associadas ao SAEB e SIMCE geram nas escolas.

\section{Necessidade e inevitabilidade da avaliação e geração de 'falso consenso'}

Alinhada à estratégia de naturalização, há uma série de mecanismos discursivos que operam em inter-relação. Um destes mecanismos é apresentar o sistema de avaliação como necessário e inevitável, forçando, assim, sua aceitação por parte dos receptores do discurso. A este se agregam estratégias orientadas a gerar a ilusão de um consenso sobre estes sistemas de avaliação, apoiado pela ideia de que sua expansão, por diferentes países - apresentada novamente como espontânea e natural -, é um argumento que justifica sua existência a nível local.

A réplica destas estratégias a nível local fica evidente em alguns fragmentos ilustrativos. No Brasil, por exemplo, as relações que o governo faz com as avaliações externas conta com forte apelo para formação de falsos consensos. Afirma-se que o atendimento às exigências globais implica na formação de uma estrutura avaliativa com parâmetros mundiais. Exemplo disso é a relação feita entre as avaliações locais, como o SAEB e o PISA. Em documento 
dedicado a apresentar o PISA como exemplo internacional de avaliação, destaca-se a importância da avaliação em todo o mundo na preparação dos jovens para as etapas futuras de ensino. No caso brasileiro, o teste é realizado a partir do $7^{\circ}$ ano do ensino fundamental (ano em que na maioria dos países ocorre a transição da educação básica obrigatória fundamental para o ensino médio), para jovens com faixa etária de 15 anos.

Contextualizada no cenário mundial, e vista sob o prisma da desigualdade que marca seu sistema de ensino, a situação do Brasil é preocupante. O ensino médio de boa qualidade para a maioria ainda é um ideal a ser colocado em prática. No entanto, vista sob o prisma da vontade nacional expressa na Lei de Diretrizes e Bases da Educação Nacional (LDB), a situação brasileira é rica de possibilidades. A Nação anseia por superar privilégios, entre eles os educacionais; a economia demanda recursos humanos mais qualificados. Essa é uma oportunidade histórica para mobilizar recursos, inventividade e compromisso na criação de novas formas de organização institucional, curricular e pedagógica que superem o status de privilégio que o ensino médio ainda vem tendo no Brasil. A partir das mudanças introduzidas pela nova LDB, no marco desta nova legislação, a avaliação passou a ser considerada como uma ferramenta estratégica para orientar as políticas públicas de educação. Assim, a participação do Brasil no Programa Internacional de Avaliação de Estudantes (PISA) ocorre dentro deste contexto, com o propósito de gerar dados de qualidade, examiná-los com competência e tirar as lições e implicações de políticas procedentes (BRASIL, 2001, p. 08-09).

Buscando o entendimento de haver consenso sobre a necessidade de mudanças no cenário educacional brasileiro, o trecho acima destaca que a participação do Brasil no PISA permitirá que o país gere dados de qualidade para melhorar a formação oferecida.

Nesta mesma direção, um exemplo ilustrativo no caso chileno é o seguinte fragmento, no qual Eyzaguirre y Fontaine (1999, p. 109-110, tradução nossa) assinalam:

Se o Chile é um dos pioneiros neste tipo de medições na América Latina, a aplicação massiva de provas de desempenho destinadas a medir os sucessos das aprendizagens obtidos pelo sistema escolar é uma prática comum em um grande número de países [...]. Estas avaliações exercem grande influência no processo de ensino-aprendizagem e nelas se tem lançado grandes esperanças de melhoria da qualidade da educação. Há, também, um grande grupo de detratores que argumentam que estas avaliações são frequentemente injustas e que têm o poder de degradar o ensino. Para muitos, a avaliação estandardizada e transparente seria uma das ferramentas fundamentais para melhorar a qualidade da educação: que os professores e as escolas, em certo modo, prestem contas sobre a aprendizagem dos alunos, naturalmente, os leva a concentrar e intensificar seus esforços em tal sentido. As provas estimulariam as escolas a superar-se e competir por seu prestígio ou seu financiamento.

Se inicia o argumento com a ideia de que a prática dos sistemas de avaliação foi estendida para uma grande quantidade de países - dentre os quais o Chile aparece como 
exemplo pioneiro -, o qual parece justificar sua necessidade e importância. Este argumento vem seguido de estratégias já mencionadas: naturalização do contexto de mercado e competência em que se enquadram estas avaliações, assim como os efeitos positivos que emanam delas, estabelecimento de uma relação direta entre estas e o conceito de qualidade.

\section{Conceito vazio de qualidade e equivalência gradual com resultados de aprendizagem}

Como destacamos em outra seção deste artigo, a omissão da discussão sobre o conteúdo ou significado do conceito de 'qualidade da educação' é característica do discurso que promovem as OIs, pois permite manter a ilusão de consenso por meio de um slogan universalmente aceito, evitando posicionamentos sobre o que se considera uma 'boa educação'.

A nível local, se observa a réplica das mesmas estratégias, que apontam a um esvaziamento do conceito de qualidade, transformando-a em equivalente a resultados de aprendizagem mensurados por meio de sistemas de avaliação. No Brasil, uma das mais importantes políticas promovidas é o Plano Nacional de Educação. Produzido para servir de guia para a educação do país por um período de 10 anos, o Plano está em sua segunda versão (2014-2024), e divide-se em 20 metas e um grande número de estratégias. A meta mais significativa, considerando o grande número de estratégias que dispõe (36 ao total), é a de número 7 (exatamente aquela que vincula qualidade da educação às avaliações externas).

Meta 7: fomentar a qualidade da educação básica em todas as etapas e modalidades, com melhoria do fluxo escolar e da aprendizagem, de modo a atingir as seguintes médias nacionais para o Ideb: 6,0 nos anos iniciais do ensino fundamental; 5,5 nos anos finais do ensino fundamental; 5,2 no ensino médio (SAVIANI, 2014, p. 30).

Sem definir os elementos constituintes de uma educação de qualidade, o documento vai destacando estratégias para que o país - e suas escolas - adeque-se às formas de avaliação por resultados, o que garantiria uma educação com qualidade superior sempre que as metas sejam alcançadas.

O seguinte exemplo ilustra, para o caso chileno, a reprodução das estratégias das OIs a nível local:

No Chile, avaliar o desempenho do sistema educacional se tornou necessário uma vez que que o sistema havia alcançado o estado de prover acesso igualitário à educação, porém as pessoas começaram a questionar a equidade do serviço oferecido. Juntamente com o oferecimento de educação para todos, todas as crianças do sistema devem receber educação igualitária em termos de 
qualidade. As autoridades podem determinar se isto ocorre ou não por meio de programas nacionais de avaliação (HIMMEL, 1996, p. 111, tradução nossa).

A citação anterior reitera o discurso já mencionado como parte da agenda global de Educação para Todos, no sentido da necessidade que se constrói a partir dos anos 1990 de concentrar os esforços na qualidade, uma vez que a cobertura havia deixado de ser um problema. Além disso, a qualidade aparece no fragmento como imediatamente ligada à necessidade de estabelecer sistemas nacionais de avaliação.

\section{Responsabilização dos usuários da avaliação}

Mencionou-se, anteriormente, como parte da Agenda Globalmente Estruturada das OIs, a correspondência da agenda de qualidade com o deslocamento da responsabilidade do Estado para os atores da escola e as famílias, aspecto que forma parte da concepção da Educação como mercadoria. Esta linha de responsabilização se observa, também, a nível local.

No Brasil, a associação de qualidade das práticas educativas ao que o professor faz em sala de aula é direta. Ainda que seja evidente essa relação entre qualidade das práticas educativas e qualidade da educação (aprendizagem), é preciso, como dissemos anteriormente, destacar que há fatores externos que devem ser considerados e, muitas vezes, são mencionados nos documentos apenas como estratégia de convencimento, sem, no entanto, haver clara proposta de enfrentamento das dificuldades.

Para melhor caracterizar as práticas pedagógicas, é importante investigar como são as práticas avaliativas empregadas pelos professores, com destaque para as posturas dos docentes sobre o tema, os objetivos traçados, os diferentes instrumentos empregados e os usos que fazem dos processos avaliativos. Com o aumento da importância atribuída aos testes cognitivos presentes nas avaliações em larga escala, deve-se verificar também de que forma eles influenciam as avaliações em sala de aula (BRASIL, 2018, p. 28).

A avaliação teria condições de revelar pontos necessários à uma prática mais adequada em sala de aula, sendo o professor o principal responsável por tais assimilações.

No Chile, por sua vez, os documentos analisados dão conta de uma responsabilização dos usuários do sistema de avaliação pelos problemas que estes experimentam, tal como ilustram os seguintes fragmentos.

Apesar dos avanços durante os últimos anos, a informação disponibilizada pelo SIMCE ainda é subutilizada por parte das escolas e docentes, que são o principal elo na cadeia de qualidade. Este tipo de uso aponta ademais para a 
construção de capacidades nos docentes e diretores das escolas (MECKES, 2007, p. 361, tradução nossa)

Os usos pedagógicos da informação de resultados resultavam muito restritos, dado que a informação reportada aos docentes muitas vezes carecia de significado para orientar suas práticas. Ademais, detectou-se que o uso da informação de resultados, por parte dos pais e responsáveis, era praticamente nulo (BRAVO, 2011, p. 195, tradução nossa)

Em ambos os exemplos, Brasil e Chile, os problemas não se situam no sistema de avaliação propriamente dito, tampouco nas políticas governamentais que associam pressões e incentivos a seus resultados, mas ao mau uso, ou uso nulo, por parte de professores e pais, dos resultados, assim como às más práticas que as escolas têm gerado em concessão com as provas.

\section{Considerações finais}

A partir das análises realizadas é possível assinalar a existência de aproximações a uma Agenda Globalmente Estruturada, no sentido da instalação de uma linguagem e um discurso comum entre as OIs e os documentos de política educacional a nível local (Brasil e Chile). Os princípios que se instalam em ambos os níveis se relacionam com a expansão de uma agenda que põe no centro o conceito de qualidade e a associa diretamente à necessidade de desenvolver e instalar sistemas de avaliação a nível global e local.

A natureza ideológica destes princípios se revela no uso de certas estratégias comuns, que obedecem a interesses compartilhados pelas elites políticas de diversos contextos: Naturalização e omissão do contexto de educação neoliberal e de mercado; Tratamento do conceito de qualidade em termos genéricos, como um slogan vazio de conteúdo; Equivalência do conceito de qualidade com o de resultado de aprendizagem no contexto de sistemas de mensuração nacionais e internacionais; Legitimação destes sistemas e deslegitimação de possíveis vozes de resistência, por meio de estratégias de: apresentação da expansão dos sistemas de avaliação da qualidade a nível continental e global como surgimento espontâneo e por meio da ilusão de consenso; apresentação de seus efeitos positivos como dados, sem oferecer maior evidência a respeito; deslegitimação de possíveis perspectivas críticas; Responsabilização dos atores da escola pelos problemas nestes sistemas de avaliação, ao não utilizar, ou não saber utilizar, os dados derivados destes, reforçando uma imagem desprofissionalizante e legitimando a existência de medições.

Tratou-se aqui, em particular, os casos do SAEB e SIMCE como exemplos de políticas de avaliação que dão conta da presença de uma Agenda Globalmente Estruturada. Estes casos 
ilustrativos, entretanto, são apenas uma mostra daquilo que se constitui enquanto aparato de políticas que respondem à mesma lógica e que seguem expandindo-se a nível continental, como ocorre com as recentes políticas de carreira docente no Brasil e Chile, nas quais se repetem as mesmas estratégias analisadas no presente artigo.

AGRADECIMENTOS: Parte desta Pesquisa contou com o apoio da Coordenação de Aperfeiçoamento de Pessoal de Nível Superior (CAPES) e da Fundação de Apoio ao Desenvolvimento do Ensino, Ciência e Tecnologia do Estado de Mato Grosso do Sul (FUNDECT)

\section{REFERÊNCIAS}

ARAÚJO, C. H.; LUZIO, N. Avaliação da Educação Básica: em busca da qualidade e eqüidade no Brasil. Brasília, DF: Instituto Nacional de Estudos e Pesquisas Educacionais Anísio Teixeira, 2005.

BELLEI, C. El gran experimento: Mercado y privatización de la educación chilena. Santiago de Chile: LOM, 2015.

BONAMINO, A.; FRANCO, C. Avaliação e política educacional: o processo de institucionalização do SAEB. Cadernos de Pesquisa, São Paulo, s/v, nº 108, p. 101-132, 1999. Disponível em: http://www.scielo.br/scielo.php?script=sci_arttext\&pid=S0100$15741999000300005 \& \operatorname{lng}=$ pt\&nrm=iso\&tlng=pt. Acesso em 20 de mar. 2019.

BRASIL. PISA 2000: relatório nacional. Brasília, 2001.

BRASIL. O desafio de uma educação de qualidade para todos: educação no Brasil - 19902000. Brasília, 2004.

BRASIL. Decreto $\mathbf{n}^{\mathbf{0}}$. 6.064, de 24 de abril de 2007. Dispõe sobre a implementação do Plano de Metas Compromisso Todos pela Educação. Planalto, Brasília: DF, 24 abr. 2007. Disponível em: http://www.planalto.gov.br/ccivil_03/_ato20072010/2007/decreto/d6094.htm. Acesso em 21 mar. 2019

BRASIL. Avaliações da educação básica em debate: ensino e matrizes de referência das avaliações em larga escala. Brasília, 2013.

BRASIL. Sistema de avaliação da educação básica: documentos de referência. Versão 1.0. Brasília, DF: INEP, 2018.

BRASIL. Portaria $\mathrm{n}^{\circ} .271$, de 22 de março de 2019. Estabelece as Diretrizes do Sistema de Avaliação da Educação Básica (SAEB). Diário oficial da União, Brasília: DF, 25 mar. 2019. Seção 1. Disponível em: http://download.inep.gov.br/educacao_basica/saeb/2019/legislacao/portaria_n271_de_22-032019_diretrizes_saeb-2019.pdf. Acesso em 20 mar. 2019. 
BRAVO, J. SIMCE: pasado, presente y futuro del sistema nacional de evaluación. Estudios Públicos, s/v, n. 123, 2011.

CAMPBELL, C.; LEVIN, B. Using data to support educational improvement. Educational Assessment, Evaluation and Accountability. v. 21, p. 47-65, 2009.

COMISIÓN SIMCE. Informe Ejecutivo Equipo de Tarea para la Revisión del Sistema Nacional de Evaluación de Aprendizajes. Santiago: Agencia de Calidad de la Educación, 2015.

CONTRERAS, J. Autonomia de professores. São Paulo: Cortez, 2002.

DALE, R. X. Globalisation and education: demonstrating a 'common world educational culture' or locating a 'globally structured educational agenda? Educational Theory, v. 50, n. 4, p. 427-448, 2000.

DOBBINS, M.; MARTENS, K. Towards an education approach a la finlandaise? French education policy after PISA. Journal of education policy. v. 27, n. 1, p. 23-43, 2012.

EYZAGUIRRE, B.; L. FONTAINE. ¿Qué mide realmente el SIMCE?. Revista de estúdios públicos, s/v, n. 75, p. 107-161, 1999.

HIMMEL, E. Impacto social de los sistemas de evaluación del rendimiento escolar: el caso de Chile. En: Álvarez, B. y Ruiz-Casares, M. (Ed.). Evaluación y Reforma Educativa: Opciones de Política. Santiago: PREAL, 1997.

HIMMEL, E. National Assessment in Chile. In: BANCO MUNDIAL. National Assessments: Testing the System. Washington, D.C.: The World Bank, p. 111-128, 1996.

LEVIN, B. Mobilising research knowledge in education. London Review of Education. Vol. 9, n. 1, 2011.

MECKES, L. El SIMCE: su desarrollo y desafíos actuales. Pensamiento Educativo, vol. 33, p. 160-178, 2003.

SAVIANI, D. Plano Nacional de educação: PNE 2014-2024. Campinas: Autores Associados, 2014.

SCHIEFELBEIN, E. Análisis del SIMCE y sugerencias para mejorar su impacto en la calidad. La realidad en cifras. Santiago: FLACSO, p. 241-280, 1998.

SCHRIEWER, J.; MARTÍNEZ, C. Constructions of Internationality in Education. In: STEINER-KHAMSI, G. (ed.). The global politics of educational borrowing and lending. New York and London: Teachers College, Columbia University, p. 29-53, 2004.

SCHWARTZMAN, S.; COX, C. Las agendas pendientes de la educación. In: Las Políticas Educativas y la Cohesión Social en América Latina. Santiago, Chile: Uqbar Editores, 2009. 
UNESCO. Los sistemas de medición y evaluación de la calidad de la educación.

Documentos del Laboratorio Latinoamericano de Evaluación de la Calidad de la Educación, 1997.

UNESCO. Educação para Todos: o compromisso de Dakar. Brasília, 2000.

UNESCO/OREALC. Balance de los 20 años del Proyecto Principal de Educación en América Latina y el Caribe. Santiago, 2001.

\section{Como referenciar este artigo}

SANTOS, F. A. dos; PETOUR, M. T. F. Internacionalização dos sistemas de avaliação: evidências de Brasil e Chile. Revista Ibero-Americana de Estudos em Educação, Araraquara, v. 14, n. esp. 3, p. 1829-1846, out., 2019. E-ISSN: 1982-5587. DOI: 10.21723/riaee.v14iesp.3.12766

Submetido em: 25/03/2019

Revisões requeridas: 22/04/2019

Aceito em: 17/05/2019

Publicado em: 30/08/2019 